\title{
Variations in Badger (Meles meles) Sett Microclimate: Differential Cub Survival between Main and Subsidiary Setts, with Implications for Artificial Sett Construction
}

\author{
Yayoi Kaneko, ${ }^{1,2}$ Chris Newman, ${ }^{1}$ Christina D. Buesching, ${ }^{1}$ and David W. Macdonald ${ }^{1}$ \\ ${ }^{1}$ Wildlife Conservation Research Unit, Department of Zoology, Recanati-Kaplan Centre, University of Oxford, Tubney House, \\ Abingdon Road, Tubney, Oxon OX13 5QL, UK \\ ${ }^{2}$ Wildlife Conservation Laboratory, Division of Ecosciences, Tokyo University of Agriculture and Technology, Saiwaicho 3-5-8, Fuchu, \\ Tokyo 183-8509, Japan \\ Correspondence should be addressed to Yayoi Kaneko, ykaneko@cc.tuat.ac.jp \\ Received 10 March 2010; Revised 29 June 2010; Accepted 5 August 2010 \\ Academic Editor: Cajo J. F. ter Braak \\ Copyright (๑) 2010 Yayoi Kaneko et al. This is an open access article distributed under the Creative Commons Attribution License, \\ which permits unrestricted use, distribution, and reproduction in any medium, provided the original work is properly cited.
}

\begin{abstract}
Maintaining homeothermy is essential for mammals, but has considerable energetic costs. In this study, we monitored the internal conditions of setts within five European badger (Meles meles) social groups during the cub-rearing season, that is, February to July, in 2004. Sett temperature showed substantial and significant variation over this period, while relative humidity remained stable throughout. Microclimate was least stable during the period for which cubs remain entirely below ground between February and April; however here the instrumented main sett demonstrated a much warmer and more stable temperature regime than did nearby subsidiary outliers. We thus postulate that the energy budget of reproducing females could be affected by even small temperature fluctuations, militating for optimal sett choice. For comparison we also report microclimatic data from two artificial setts and found them to be markedly inferior in terms of thermal insulative properties, suggesting that man-made setts may need more careful consideration in both thermal and spatial setts network in each territory to adequately compensate the loss (e.g., destruction due to development) of a natural sett, especially as a breeding den.
\end{abstract}

\section{Introduction}

Dens are known to be important, and carefully constructed or selected, resources for various carnivores: wolves "Canis lupus" [1, 2], arctic foxes "Alopex lagopus" [3, 4], gray foxes "Urocyon cinereoargenteus" [5], polar bears "Ursus maritimes" [6], lynx "Lynx Canadensis" [7], wolverines "Gulo gulo" [8], otters "Lutra Canadensis" [9], and skunks "Spilogale gracilis" [10] are all examples of Carnivora that have been found to utilize dens in locations that can be predicted from topography, pedology, and/or habitat characteristics.

Factors determining den location and suitability could thus be particularly significant in highly fossorial species, such as the European badger Meles meles. Meles spp. (to include close Asian relatives with a similar biology; see [11]) are unusual amongst mustelids in particular, and carnivores in general, in that in some regions they form stable social groups of mixed age and sex whose members share a territory and occupy a communal diurnal resting den, termed a "sett" [12-14]. Fowler and Racey [15] measured a reduction in badger body temperature of between $1.0-8.6^{\circ} \mathrm{C}$ while at rest in winter dens, but noted that badgers still retain sufficient mobility and alertness to defend themselves or escape from possible danger, if circumstances arise.

Despite living in groups under certain resource conditions [16], badgers are solitary foragers that show a high degree of behavioural plasticity, adapting their social and spatial organisation in response to differences in the environment and changes in food availability (reviewed in $[17,18])$. The distribution of badger setts is thus determined by the availability of specific environmental resources, such as underlying geology, soil type, vegetation cover, land use, and the impact of human activity [19-26].

Macdonald et al. [26] demonstrated that the 279 sites where badgers had dug main or subsidiary setts (for definition see [27]), in Wytham Woods, Oxfordshire, UK, 
were distributed with a preference for advantageous local microclimate. Here we investigate the internal environment of the sett and test whether setts of different size and apparent significance to badgers resident in the social group (i.e., main sett versus subsidiary outlier) vary in terms of internal microclimate (temperature and humidity).

While every effort was taken to maximize sample size throughout this study, as is often the case in behavioural ecology, we were constrained by financial and time resources [28]. This study attempted to deploy limited capacity in order to achieve maximum effect by focusing on the period during which cubs are being reared, with cubs remaining exclusively below ground between birth in mid-February until weaning commences in mid-April [29], with cubs remaining more vulnerable to thermal stress until they gain semi-independence in July [14]. We establish a methodology with which to measure sett temperature both at natural and artificial setts and then focus on how observed differences in internal sett conditions might confer a detectable advantage to resident badgers. We then proceed to a focal study examining for differences between sett internal characteristics where multiple (and varied) outliers exist within a single group territory, with particular regard to the cub-rearing season. We consider whether these differences in internal sett "quality" correlate with subsequent cub philopatry (a proxy for survival in this closed population where firstyear philopatry is known to exceed $85 \%$, see [30]) and recruitment into the adult population, that is, characteristics defining successful breeding dens. As badger cubs are highly altricial and remain entirely within setts until they are at least $8-10$ weeks old [29], sett quality is posited to be influential in their early survival.

We also make a preliminary investigation of how natural setts compare with representative artificial setts, constructed for the purpose of relocating badgers as part of conservation mitigation strategies [31-34]. This strategy is often practiced in the UK by statutory governmental nature authorities, wildlife trusts, Non-Governmental Organizations (NGOs) concerned with animal protection (e.g., the Badger Trust; the Royal Society for the Prevention of Cruelty to Animals), and by independent wildlife consultancies, to translocate badgers away from areas under development or from areas where badgers may be causing damage (badgers being protected under "The Badger Act, 1992" in the UK).

\section{Materials and Methods}

2.1. Study Sites. This study was conducted at Wytham Woods, $5 \mathrm{~km}$ northwest of Oxford, UK (GPS ref: $51: 46: 26 \mathrm{~N} ; 1: 19: 19 \mathrm{~W}$; for details see $[35,36])$. Mean annual temperature over the study period was $9.6^{\circ} \mathrm{C}$ and mean annual precipitation $634.1 \mathrm{~mm}$ (Oxford Radcliffe Meteorological Station, School of Geography).

The Wytham badger population is also partly discrete geographically, with the River Thames to the north, the Oxford conurbation to the west, the major roads (A34, A420) to the south, and a large man-made reservoir to the east [36]. An average of only $3 \%$ of badgers trapped per year are
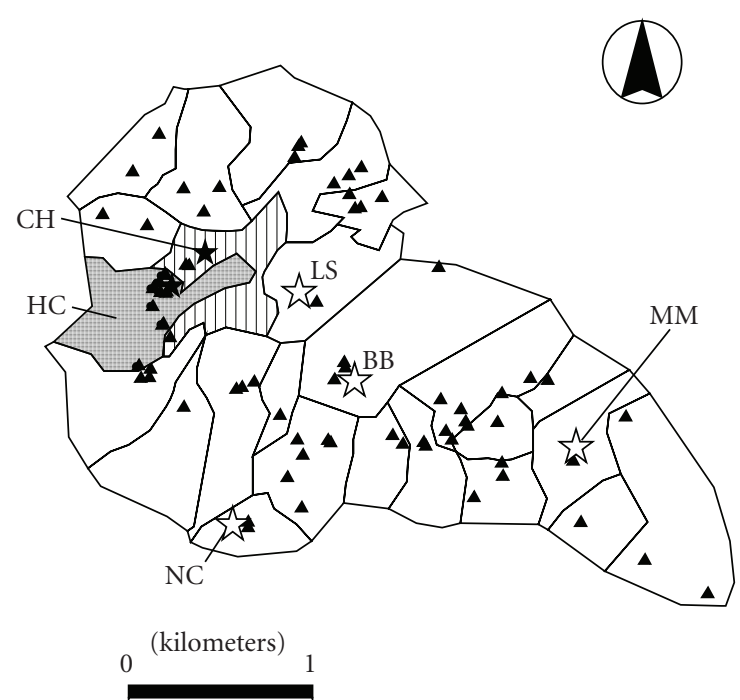

FIGURE 1: Sett locations (triangles), badger group territory boundaries (solid lines, 2003), and sett thermometer survey locations (white stars) in Wytham, 2003-2004. Logger survey locations (dots) in the Hill Copse group area (grey) and Chalet group area (stripe) with main setts (black stars).

estimated to be immigrants at this site [36]. Approximately $8 \%$ of badgers killed by road traffic in the vicinity of the woods are unmarked and likely to have arrived from outside the population [30]. Thus, the site is relatively isolated from dispersal from elsewhere.

Additional measurements were made of artificial setts in Gloucestershire, within $50 \mathrm{~km}$ of the main Oxfordshire study site.

2.2. Measuring Microclimate Conditions within Natural and Artificial Setts. A "sett thermometer probe" was constructed, consisting of a thermometer (ELE 506-124, produced by ELE International, USA) and an infrared camera (produced by SANYO Co, Japan, originally for security monitoring purposes) mounted onto a $5 \mathrm{~m}$ long flexible steel drain-rod pole communicating to a remote monitor. The camera combined with a pulley system on the tip of the pole allowed the probe to be directed within the tunnel system. A 12-volt motorcycle battery, with a transformer, powered the equipment, weighing $5.6 \mathrm{~kg}$ with a battery life of three hours on full charge.

The probe was inserted into the tunnel system with care, using the pulley system and monitor to direct progress until reaching either the end of the network or an unassailable impediment to further progress arrested further ingress.

In June and July 2003, a total of twelve trials (four trials in sett MM, four in BB, and four in LS; Figure 1; Table 1) were performed to survey three setts, each in a separate social group (see Section 2.4, below). Roper [37] and Roper and Kemenes [38] reported that badger setts differ considerably in their internal architecture, with no evidence of design consistency, especially in larger setts. From the trajectory of the probe and distance inserted, we were able to infer that all investigated setts, from an outlier (one entrance) to a 

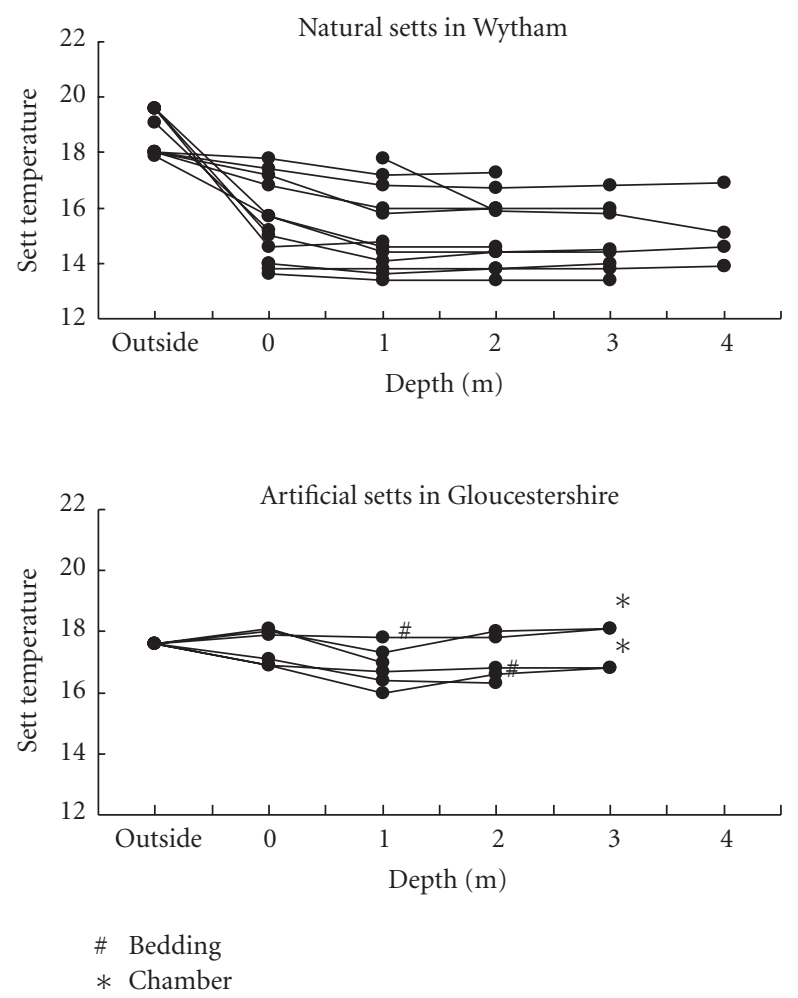

Figure 2: External and internal sett temperature at each meter depth from the entrance: four main natural setts in Wytham upper, June and July 2003 and two artificial setts in Gloucestershire (below, July 2003).

large sett (16+ entrances), could extend to a vertical depth in excess of $2 \mathrm{~m}$ beneath ground level. However, in most cases tunnel depth did not exceed $1.5 \mathrm{~m}$ in vertical section from the surface datum.

Many of our preliminary attempts to instrument setts were hampered by tree root systems, which presented often impassable impediments to probe access. Subsequently, specific setts were selected for further study where this presented less of an issue (Figure 2; Table 1). All setts were occupied by badgers (as established by a concurrent trapping regime-see Section 2.4 below) when under investigation.

In addition, we also measured two artificial setts in Gloucestershire, as their simple design provided for a comparison relevant to informing badger relocation policies. These setts were constructed by an independent environmental consultancy company in order to compensate for the destruction of a badger group's natural sett, necessitated by construction of local road improvements. The artificial setts, one with three entrances and another with four, used plastic drain pipe $30 \mathrm{~cm}$ in diameter to lead into a well-drainedcement chamber. These setts were sampled according to the same protocol detailed above. During the survey the consultancy responsible for the sett believed it to house approximately 6 badgers.

2.3. Continuous Sett Temperature and Humidity Monitoring within a Focal Group Territory in Wytham Woods, Using
Temperature Probes. Informed by this survey of three main setts over time, one of these setts (HC) was selected for more thorough investigation of diurnal changes in temperature throughout the cub-rearing season, with reference to six associated outliers closeby within the same territory (as established by baitmarking, see; [39]). Between February and August 2004, 20 temperature probes linked to data loggers ( $8 \mathrm{~K}$ Hobo waterproof temperature loggers, $-20^{\circ} \mathrm{C}$ to $+70^{\circ} \mathrm{C}$, Tempcon Instrumentation Ltd., USA) were inserted into all the setts present $(n=7)$ within this focal social group territory (group ID Hill Copse; Figure 1 and Table 2), to a depth of in excess of $2 \mathrm{~m}$. Seven loggers were inserted into 7 holes of a main sett (Sett ID HC main; Table 2), another 7 loggers were also inserted in 7 holes in a large outlier (Sett ID KH), 2 loggers were inserted in a mediumsized outlier, and one logger was inserted in each of 4 small outliers, all within this same territory. In addition, 2 non-waterproof-relative humidity/temperature loggers $(8 \mathrm{~K}$ Hobo $\mathrm{RH} /$ Temp logger; $-20^{\circ} \mathrm{C}$ to $+70^{\circ} \mathrm{C}$ with relative humidity 25\%-95\%; Tempcon Instrumentation Ltd., USA) were placed on top of the two large setts (sett ID: HC main, $\mathrm{KH})$ recording "external ambient temperature" (EAT) for reference. The loggers recorded temperature and humidity at 10-minute intervals continuously throughout the study period, and data were downloaded to a computer each month.

\subsection{Badger Population Monitoring and Philopatry Dynamics.} The Wytham badger population has been studied continuously since the 1970s [40], and an attempt has been made to trap and mark the entire population 4 times per annum since $1987[36,41]$. Note that no prebaiting is performed as part of the trapping programme, and thus the effect of trap-bait on the population's success was judged to be inconsequential. On first capture, each badger was given a unique identifying tattoo in the inguinal region [42]. Badgers trapped within their first year of life were termed "cubs", assuming a birthdate of around mid-February (see [36]). All individuals more than one year old were included in the adult age class. Of note, cubs are known to follow different, and more severe, mortality trends than adults within this badger population, warranting this distinction in our analyses $[30,36,41]$.

Morphometric measures of weight, body length (tip of snout to sacrum), and body condition (subcutaneous fat score) were recorded, inter alia, upon each capture. Between 1987 and 2004 (the interval relevant to this study), 493 individual males and 511 females contributed to a total of 6,762 trapping records. In the HC territory, 68 individuals (37 males and 31 females) were trapped (419 records). Of note, excluding 1987 (1st study year), trapping efficiency for this population has remained relatively constant throughout with a mean of $83.69 \%(\mathrm{SE}=1.32)$ of the Minimum Number Alive- (MNA-) estimated population being returned by the trapping effort from one year to the next [41]. Within this study population, dispersal between social groups has been established to be relatively low at $<20 \%$ per annum [30], with $87 \%$ of individuals maintaining site fidelity between trapping sessions and $85 \%$ of surviving cubs remaining philopatric through their first year. 
TABLE 1: Sett types and trials by the sett thermometer probe in 2003.

\begin{tabular}{|c|c|c|c|c|c|c|}
\hline \multirow[b]{2}{*}{ Sett ID } & \multicolumn{4}{|c|}{ Natural sett in Wytham } & \multicolumn{2}{|c|}{ Artificial sett in Glocestershire } \\
\hline & LS & $\mathrm{BB}$ & MM & $\mathrm{NC}$ & Sett 1 & Sett 2 \\
\hline Sett type & Main sett & Main sett & Main sett & Main sett & Unknown & Unknown \\
\hline Slope direction & $\mathrm{E}$ & SE & NE & NE & Flat & flat \\
\hline Hole number & 21 & 10 & 8 & 11 & 3 & 4 \\
\hline Trials & 4 & 4 & 4 & 1 & 3 & 3 \\
\hline Note & & & & $\begin{array}{c}\text { Impassable b } \\
\text { tree route }\end{array}$ & & \\
\hline
\end{tabular}

TABLE 2: Core internal sett temperature (CIST) in Hill Copse territory in Wytham, 2004.

\begin{tabular}{|c|c|c|c|c|c|c|c|c|c|c|}
\hline \multicolumn{3}{|c|}{ Sett ID } & $\mathrm{HC}$ main & HC flat & HC west & Oblivian & $\mathrm{HC}$ esc & $\mathrm{KH}$ & GOA & All setts \\
\hline \multicolumn{3}{|c|}{ Sett type } & Main sett & Outlier & Outlier & Outlier & Outlier & Outlier & Outlier & \\
\hline \multicolumn{3}{|c|}{ Slope direction } & NW & NW & NW & SW & SW & NW & NW & \\
\hline \multicolumn{3}{|c|}{ Distance from HC main sett $(\mathrm{m})$} & & 34 & 65 & 189 & 131 & 207 & 402 & \\
\hline \multicolumn{3}{|c|}{ Hole number } & 10 & 3 & 2 & 2 & 2 & 13 & 2 & \\
\hline \multicolumn{3}{|c|}{ Logger number (external ambient temp/RH logger) } & $8(1)$ & 2 & 1 & 1 & 1 & $8(1)$ & 1 & $20(2)$ \\
\hline & Period & $n$ & & & & & & & & \\
\hline 1 & 26th February-1st March & 10800 & 1.6 & 4.1 & 3.6 & 1.8 & 1.9 & 1.4 & 4.5 & 2.2 \\
\hline 2 & 11th-15th March & 10800 & 4.7 & 5.6 & 5.3 & 5.1 & 4.7 & 4.9 & 5.4 & 5.0 \\
\hline 3 & 25th-29th March & 8652 & 6.1 & 6.9 & & 5.4 & & 5.8 & 6.3 & 6.0 \\
\hline 4 & 8th-12th April & 10800 & 6.6 & 7.3 & 7.2 & 6.1 & 6.4 & 6.9 & 7.3 & 6.8 \\
\hline 5 & 25th-29th April & 9360 & 9.7 & 9.3 & 9.9 & 8.1 & 8.4 & 10.0 & 10.3 & 9.5 \\
\hline 6 & 7th-11th May & 10366 & 10.0 & 9.0 & 9.7 & 8.4 & 8.9 & 9.7 & 9.8 & 9.6 \\
\hline 7 & 21st-25th May & 12960 & 11.0 & 10.0 & 11.0 & 9.7 & 9.7 & 10.8 & 11.3 & 10.7 \\
\hline 8 & 5th-9th June & 13678 & 13.9 & 12.6 & 13.2 & 11.4 & 11.4 & 14.3 & 14.9 & 13.7 \\
\hline 9 & 20th-24th June & 12066 & 12.0 & 11.5 & 12.3 & 11.3 & 11.6 & 12.3 & 12.4 & 12.0 \\
\hline 10 & 5th-9th July & 10800 & 13.2 & 12.1 & 12.6 & 12.0 & 12.0 & 12.9 & 12.8 & 12.8 \\
\hline
\end{tabular}

Badger territories were established by baitmarking surveys every one or two years, commencing in $1976[17,39$, 43 ], culminating in the division of the population into 22 groups from 2003 onwards [30, 44]. For each monitored sett, the number of cubs born and their subsequent condition, philopatry, and thus survival was monitored by reference to concomitant trapping records and by direct observation at the sett. Biannual bait marking studies record that $\mathrm{HC}$ established an independent group territory from the neighbouring group (Group ID Chalet; Figure 1) in 1993, through a process of range fission and the formation of a dividing latrine-marked border. Cub continued philopatry within the territory was defined as a marked cub being recaptured after its first winter, aging one year, using only those data where individuals were recaught "at the same sett". Individuals subsequently trapped in different social groups ("dispersers") as part of the concurrent comprehensive trapping protocol throughout the woods were not included in further analyses, as their survival dynamics could not be definitively linked to temporally proximate sett characteristics (see [45]). Immigrant cubs were defined as marked cubs present in another territory in spring/summer and moving to $\mathrm{HC}$ during their first autumn/winter, and subsequently surviving.

2.5. Data Analyses. Data analyses were three-fold: (1) comparison of temperature in both natural and artificial setts using one-way, and two-way, ANOVA, (2) comparison of daily (two month periods; February-March, April-May, and June-July) and seasonal differences in sett temperature, using ANOVA and GLM, (3) continuous five-day temperature (Periods 1-10, Table 2) and humidity readings at 10-12-day interludes between 26 February and 9 July (2004) at the main sett and six outliers with a single, focal social group, using ANOVA GLM.

Cub philopatry was recorded directly from the trapping records, corroborated by sett observations. Capture-markrecapture models have been found to consistently overestimate badger numbers in high-density populations where trapping efficiency is high [46] and MNA-based estimates better allow comparison with previous major studies [36, 41]. The benefits of a reliable, irrefutable minimum thus 
were judged here, with a small sample size and exceptionally high (re-) trapping success, to exceed the risk of a moderate negative bias on ultimate population size that may result from a more complex model $[41,47,48]$. Also, genetic evidence indicates that parenthood is consistently well accounted for amongst the trapped sample in this study population $[49,50]$.

The relationship between the frequency of rapid per diem temperature changes within seasons, and badger cub continued philopatry (and de facto survival) in each sett was examined using Test and CI for two proportions, which performs a test of two binomial proportions: $\mathrm{H} 0$ : $\mathrm{P} 1-\mathrm{P} 2$ $=\mathrm{P} 0$ versus $\mathrm{H} 1: \mathrm{P} 1-\mathrm{P} 2 \neq \mathrm{P} 0$, where $\mathrm{P} 1$ and $\mathrm{P} 2$ are the proportions of success in populations 1 and 2, respectively, and P0 is the hypothesized difference between the two proportions. In addition, the results were qualified using a Fisher's Exact Test.

For these statistical analyses, one-/two-way ANOVA and GLM were performed using Minitab 13, and Fisher's Exact Test was performed with SAS (SAS Institute), with alpha set at 0.05 .

\section{Results}

\subsection{Validation of Temperature Probe Measurement in Natural and Artificial Setts.}

3.1.1. Natural Setts. From the 3 occupied setts surveyed in June and July 2003, with four trials in each sett (Figure 2; Table 1), we established a mean sett entrance temperature $(\mathrm{SET})$ of $16.3 \pm 1.2^{\circ} \mathrm{C}(\mathrm{SD})\left(n=12\right.$ range; $\left.13.4-17.8^{\circ} \mathrm{C}\right)$, significantly lower than external ambient temperature (EAT) (two-way ANOVA: $F_{1,17}=38.5 ; P<.05$ ), which averaged 18.7 $\pm 0.8^{\circ} \mathrm{C}(\mathrm{SD})\left(n=12\right.$; range $\left.17.9-19.6^{\circ} \mathrm{C}\right)$. At progressively deeper (i.e., distance from tunnel entrance) points into the tunnel system, however, temperature did not vary significantly (two-way ANOVA in each comparison: $F_{1,8-16}$ $=0.08-2.9, P>.05: 1 \mathrm{~m}: 15.5 \pm 1.1(\mathrm{SD}){ }^{\circ} \mathrm{C}, n=9$, range $13.4-17.8^{\circ} \mathrm{C} ; 2 \mathrm{~m}: 15.0 \pm 1.1^{\circ} \mathrm{C}, n=8$, range $13.4-$ $17.3 ; 3 \mathrm{~m}: 15.3 \pm 1.0^{\circ} \mathrm{C}, n=5$, range $13.4-16.8^{\circ} \mathrm{C} ; 4 \mathrm{~m}: 14.9$ $\pm 1.3^{\circ} \mathrm{C}, n=4$, range $13.9-16.9^{\circ} \mathrm{C}$ ). That is, natural setts were characterized by a microclimate that prevailed from the tunnel entrance onwards.

3.1.2. Artificial Setts. In the two artificial setts, six trials were performed in July 2003, due to limited availability of the site (Figure 2; Table 1). These setts were known to be occupied while measurements were made, from the observations of the supervising consultancy company implementing the mitigation measure. In all cases, temperature showed an average of 16.8-17. $6^{\circ} \mathrm{C}$ at distances from tunnel entrance of between 0 and $3 \mathrm{~m}$. Unlike the natural setts, this was not significantly different to the EAT of $17.6^{\circ} \mathrm{C}$ (one-way ANOVA: $n=6 ; F_{1,11}$ $=0.25 ; P>.05)$; nor did temperature vary in any betweendepth comparison from $0 \mathrm{~m}$ to $3 \mathrm{~m}$ (one-way ANOVA: $F_{1,5-11}$ $=0.05-3.1 ; P>.05)$; that is, these artificial setts did not create an internal microclimate significantly different from external conditions at any distance from the surface. Furthermore, in two trials the sett camera reached an empty nest chamber in these artificial setts, but still recorded no statistically significant difference to the EAT (one-way ANOVA: $F_{1,13}=$ $0.1, P>.05,1-3 \mathrm{~m}: 17.1 \pm 0.7(\mathrm{SD}){ }^{\circ} \mathrm{C}, n=12$, chamber: 15.7 and $18.1^{\circ} \mathrm{C}$ ). In two of these trials, the sett camera was impeded on the way into chambers by a barrier of grass, bedding, and plastic sheeting material at depths of $1 \mathrm{~m}$ and $2 \mathrm{~m}$, respectively.

Based on these natural and artificial sett measurement results, temperature did not vary at distances of greater than $2 \mathrm{~m}$ into tunnel systems. This defined "core-internal sett temperature" (CIST).

3.2. Daily Temperature and Relative Humidity Regime at Different Natural Setts within a Single Territory. Focusing on a single group territory containing a main sett and six outliers (varying in size), the 20 loggers positioned at a depth in excess of $2 \mathrm{~m}$ revealed a mean trend where CISTs increased from 08:00, peaked around 14:00-15:50 $\left(5.3^{\circ} \mathrm{C}\right.$ in February-March, $n=2,520,9.9^{\circ} \mathrm{C}$ in April-May, $n=3,636$, $13.5^{\circ} \mathrm{C}$ in June-July, $\left.n=3,036\right)$, and then decreased to the lowest diurnal temperatures around 04:00-05:50 $\left(3.5^{\circ} \mathrm{C}\right.$ in February-March, $n=1,800,8.5^{\circ} \mathrm{C}$ in April-May, $n=3,612$, $12.1^{\circ} \mathrm{C}$ in June-July, $\left.n=3,060\right)$. These loggers recorded a study period average temperature of $9.5^{\circ} \mathrm{C} \pm 3.7(\mathrm{SD})$, ranging from $-5.3^{\circ} \mathrm{C}$ to $34.0^{\circ} \mathrm{C}$ between 26 February and 10 July $2004(n=298,246)$. The difference between daily maximum and minimum was not significant in April-May (04:00-05:50, ANOVA GLM: $\left.F_{1,2519}=0.2 ; P=.64\right)$; however it was significant in other bimonthly intervals (ANOVA GLM: February-March: $F_{1,2519}=75.2, P=.001$; June-July: $\left.F_{1,2519}=6.2, P=.001\right)$.

The mean EAT at the largest two setts (the main sett and principal outlier) ranged from $-5.3^{\circ} \mathrm{C}$ to $26.0^{\circ} \mathrm{C}$ during the study. Temperature peaked in the afternoon between 12:00$17: 50\left(3.9-15.9^{\circ} \mathrm{C}\right.$ on average, $\left.n=1,850\right)$ with no significant differences observed between the other recording intervals, 12:00-13:50, 14:00-15:50, and 16:00-17:50 (ANOVA, GLM, HC main: $\left.F_{1,11}=0.32 ; P=.15\right)$. The significantly lowest temperatures occurred around dawn, at 04:00-05:50 (-2.8$14.8^{\circ} \mathrm{C}$, ANOVA GLM, HC main: $F_{1,5658}=1062.3 P=.001$; $\left.\mathrm{KH}: F_{1,5650}=1515.9, P=.001\right)$.

Mean external relative humidity at this main sett and principal outlier ranged from $31.6 \%$ to $98.5 \%$ between February and July 2004. In each period, relative humidity peaked at 08:00-09:50 $(n=650$; average $82.6 \%$; range $63.9 \%-$ $93.4 \%)$ and continued to decrease to its lowest point at 17:00-18:50 ( $n=650$; average 69.0\%; range 63.9-83.0\%).

\subsection{Seasonal Temperature and Humidity Regime at Different} Natural Setts within a Single Territory. In winter, internal sett temperatures were significantly warmer than the external air; that is, considering all ten recording periods (Figure 3 ) while CIST was lowest in late February (Period 1), it was significantly higher than EAT (ANOVA GLM: $F_{1,719}=68.7 ; P$ $=.001)$. By contrast we observed a spring similarity between internal and external conditions: in March (Periods 2 and 3), CIST and EAT fluctuated in parallel, with no observed 


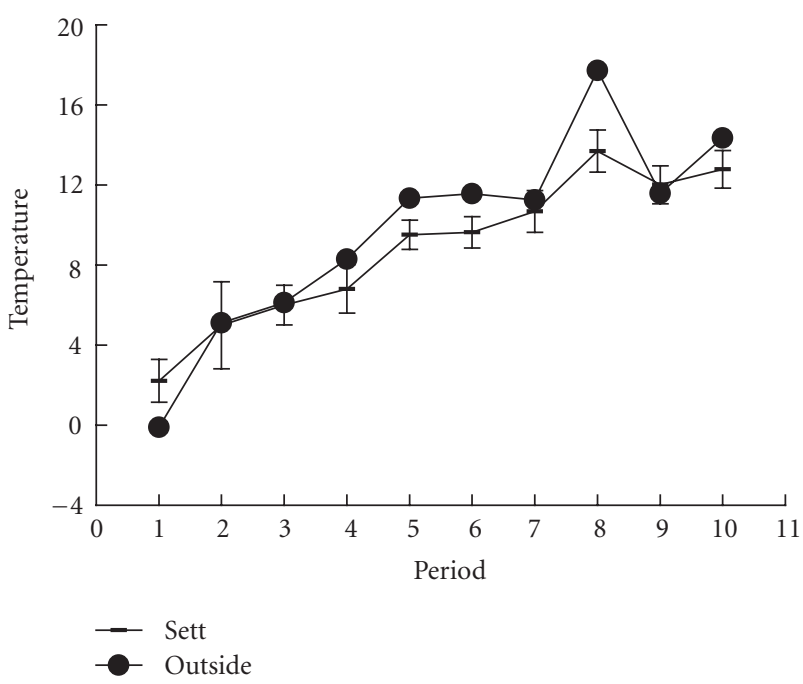

Figure 3: External (EAT) and internal (CIST) sett temperature change over ten periods between late February and early July 2004. Period 1: 26th February- In 2004, February had 29th. So there is no problem in 1st March for the five continuous days monitoring, same as other period. Period 2: 11th-15th March, Period 3: 25th29th March, Period 4: 8th-12th April, Period 5: 25th-29th April, Period 6: 7th-11th May, Period 7: 21st-25th May, Period 8: 5th-9th June, Period 9: 20th-24th June, and Period 10: 5th-9th July.

significant differences (ANOVA GLM: $F_{1,719}=1.7$ and 1.0; $P=.13$ and 0.20). From April (Period 4) onwards, CIST was slightly cooler than EAT but not significantly different (ANOVA GLM: $F_{1,719}=1.17 ; P=.1$ ). As spring progressed into summer, however, the setts became significantly cooler than external air temperature, with CIST significantly lower than EAT in Periods 5, 6, 8, and 10 (late April to early July, ANOVA GLM: $F_{1,719}=7.5-80.1 ; P=.001$ each).

Average external relative humidity, by contrast, showed variation from its lowest point in late May $(66.7 \%)$ to its highest in early March (84.6\%), but with no significant differences between periods (ANOVA GLM: $F_{1,719}=1.7-$ $72.7 ; P=.3-1.0)$.

Between these setts in the HC territory, the main sett stood out from outliers only in Period 1 (Table 2), being significantly warmer, in terms of CIST, than two outliers facing south (ANOVA GLM: $F_{1,719}=10.8$ and $12.8 ; P=.001$ each) and cooler than the northwest-facing outliers (ANOVA GLM: $F_{1,719}=6.6$ and 5.6; $P=.001$ each). The main sett was, however, not significantly different to the largest outlier, facing northwest, (ANOVA GLM: $F_{1,719}=962.8 ; P=.42$ ) or to a small north-west facing outlier (ANOVA GLM, $F_{1,719}=$ $26.58, P=.1)$.

Furthermore, amongst outliers, the most extreme differences were observed in Period 8 (early June) and occurred between north-west-facing and southerly exposed outliers, with the two south facing outliers recording significantly cooler CIST values than the other outliers through interoutlier comparison (ANOVA GLM: $F_{1,719}=0.5-2.5 ; P=.001$ ).

Continuous monitoring of CIST also revealed that sett microclimatic conditions could change rapidly. Changes in

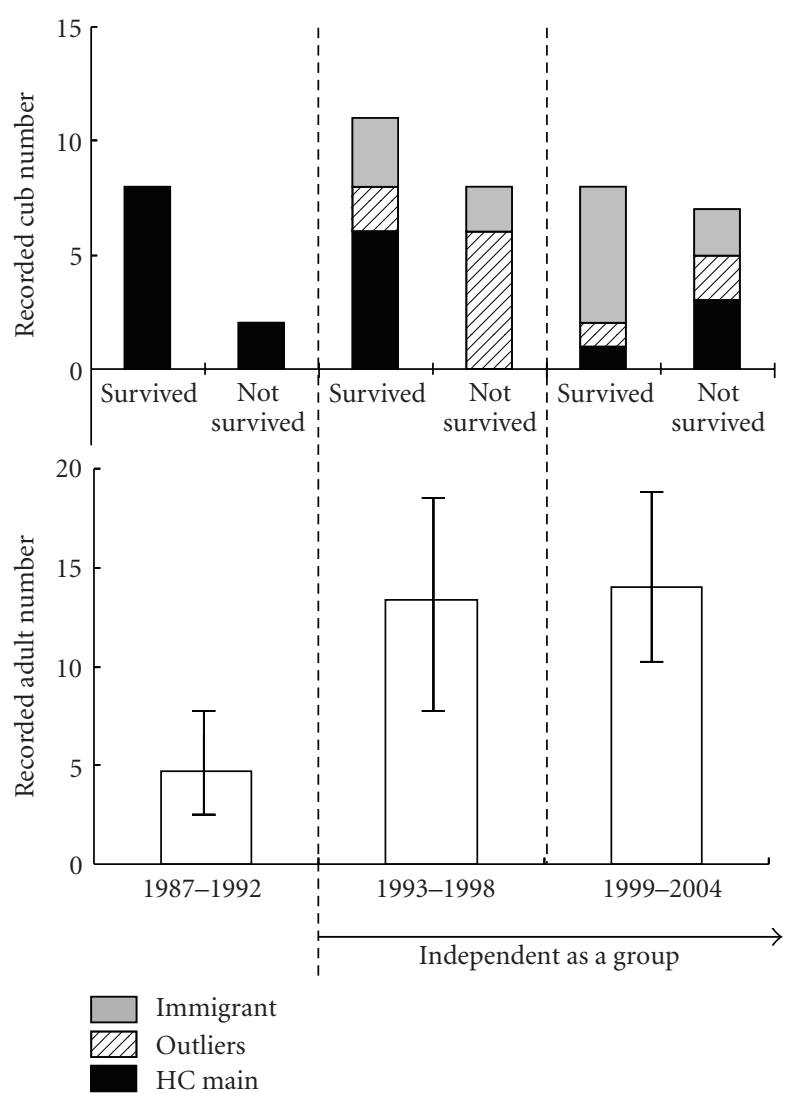

Figure 4: Cub survivorship (above) and adult numbers (below) in the Hill Copse territory in Wytham between 1987 and 2004.

excess of $2^{\circ} \mathrm{C}$ in 6 hours were noted more frequently in March $(n=21)$ and April $(n=18)$ and less frequently in May $(n=$ 3 ), with none in June (Test and CI for two proportions: $Z=$ $7.53 ; P=.001)$.

3.4. Continuing Cub Philopatry within the HC Territory. From 1987-1992, prior to the fission that established HC as an independent group territory, $\mathrm{HC}$ had on average $4.7 \pm$ 2.4 (SD) adult badgers present. This increased significantly to $13.3 \pm 5.0(\mathrm{SD})$ adults in the postfission interval, 19931998 (one-way ANOVA: $F_{1,11}=14.4 ; P=.001$, Figure 4 ). Subsequently, in the period 1999-2004, no further significant increases in the number of adults were observed (14.0 \pm 3.1 (SD); one-way ANOVA: $F_{1,11}=0.08 ; P=.79$, Figure 4). Between 1987 and 2004, 29 cubs were recorded amongst the setts distributed through the HC territory. Defining here "continuing philopatry" (with implicit survival), 15 out of 18 cubs $(83.3 \%)$ were recaptured as yearlings at the main sett, significantly higher than the three out of 11 cubs recorded at the outliers $(27.3 \%)$ (Test and CI for two proportions: $Z=3.49 ; P=.001$; Fisher's Exact Test: $P=.0051)$. This is strongly indicative that the main sett processes characteristics that make it a more suitable site for cubs to survive in, and exhibit continuing philopatry, than contemporary outliers.

Examining only data prior to group fission and the establishment of HC as an independent social group (19871992, at which time HC was a large outlier of an adjacent 
social group; Figure 4), 10 cubs were born, of which 8 continued to survive and remained philopatric to become at least yearlings, with only 2 cubs never being caught again after their first year in this group, or in any other contiguous or peripheral group within the discrete population; that is, $\mathrm{HC}$ was already proving to be a quality outlier within its previous group affiliation.

Post-fission, examining the period 1993-1998, 14 cubs were born in this newly formed territory. Of the 6 of these cubs first recorded from the HC main sett, all survived and were recaptured as yearlings. By contrast, the outliers proved less successful in terms of cub survival and persistent philopatry, with only 2 of the 8 cubs born in HC outliers ever being recorded by the population trapping protocol on a subsequent occasion (i.e., implicit mortality): a significantly lower proportion than at the main sett (Test and CI for two proportions: $Z=4.9 ; P=.001$, but no difference in another test; Fisher's Exact Test: $P=.64$ ).

Examining the period after which adult numbers stabilized, 1999-2004, 7 cubs (4 at the main sett and 3 at the outliers) were born in the territory, but only one main sett cub and one outlier cub persisted in the population records until adulthood (Test and CI for two proportions: $Z=-0.24$; $P=.81$; Fisher's Exact Test; $P=.016$ ). Examining continuing cub philopatry at the six HC outliers over this same period, 14 cubs were born between 1993-2004 and persistence in the trapping record through the first year was established for, respectively, 2 out of $6(67 \%) ; 2$ out of $2(100 \%) ; 2$ out of 2 (100\%); zero out of 3 ; and zero out of one; with no cubs born at the final outlier. Recruitment of immigrant cubs from neighbouring social groups increased from 3 (1993-1998) to 6 (1999-2004), suggesting better first-year survival amongst surrounding social groups than observed for philopatric cubs during this period.

Note. No data on cub survival or sett fidelity were available for the newly established artificial setts.

\section{Discussion}

Badger sett temperatures (CISTs) showed a clear pattern of daily stability, albeit with considerable seasonal variation. This pattern of stability was most pronounced in the main sett and the largest outlier. By contrast, in the two artificial setts, daily CIST fluctuated in parallel with EAT. Compared to daily external temperature changes, the insulating effect of the natural setts was manifest and limited variation in internal temperatures by reducing heat flux. Thus natural badger setts remained warmer than the EAT in the winter, but cooler than the EAT during the summer, especially at depths greater than $2 \mathrm{~m}$ (CIST).

Maintaining homeothermic regulation is crucial for mammals, but incurs considerable energetic costs [51]. The lower the environmental temperature the more energy the animal has to commit to maintaining its constant body temperature [52]. Altricial neonates are especially vulnerable to thermal compromise (see e.g., [53]), and thus many carnivore species utilise breeding dens (see e.g., [54-56]). Badgers are an exemplar of such behaviour, being semifossorial and accomplished excavators [57]. Their young are extremely vulnerable to mortality in the first year $[35,36]$, with their eyes opening at five weeks [14] rather than at onetwo weeks as with puppies and kittens [58], and they struggle to achieve social integration into their group [29].

Badger cubs are born and suckled between February and May [14], and we acknowledge here the potential for un-observed pre-emergence mortality to occur within the monitored setts (reported to be as high as $25 \%$ in some studies; see $[36,59])$. Simply welfare legislation and responsible ethical practice prohibited us from trapping cubs pre-weaning, and thus we focus here on post-weaning survival and philopatry dynamics, which nevertheless provide informative values. By facilitating energy conservation during the more energetically demanding periods of gestation and lactation, an insulated and thermally regulated sett (den) environment should benefit female reproductive fitness and also increase offspring survival rates by aiding cub thermoregulation. In this study, we observed that, during March and April, when unsettled spring weather leads to rapid variations in CIST, that the monitored main sett had a significantly more stable internal microclimate than outliers within the same group territory. Indeed, cubs born at this more stable main sett survived to demonstrate significantly greater continuing philopatry than did cubs born at associated outliers, especially in the period prior to 1999, after which adult numbers in the recently formed new territory stabilized, reducing the opportunity for recruitment into the group due to social, rather than environmental pressures [29]. This effect may also be moderated by indirect benefits; cubs are vulnerable to infanticide [18] and thus are vulnerable during periods without maternal care [29]; consequently warmer main sett temperatures should also result in mothers reducing time spent collecting bedding, compared to females raising their cubs at less stable/cooler outliers [57]. Selecting optimal sites (see also [26]) and digging setts with sufficient complexity and insulative capacity to maximize cub survival and philopatry until maturity (i.e., persistence in the comprehensive population record for this study site) are thus clearly important in badger biology. Badgers would be expected to attempt to exploit the most advantageous sites first and adapt their distribution to benefit from other quality sett sites over time. The focal HC-territory in this study had a socio-spatial system where the principal outlier had 13 entrances and was, in terms of entrances, at least as large and active as the historical main sett with 10 entrances (recognizing that the classification of setts is somewhat arbitrary; see $[27,59])$. No obvious differences in temperature or humidity were observed between this outlier and the main sett. This may be indicative of how the process of territory subdivision, through fission, operates resources and space permitting; this large outlier could potentially also fission from $\mathrm{HC}$ in time as it seems to have an internal environment consistent with that of a main sett. However, in the Wytham Woods' high-density population $[42,43]$, available space may limit the potential for further viable subdivision, although the increasing number of immigrant cubs observed at outliers may underscore the mechanisms militating for fission. Of 5 smaller outliers within the group territory, north-westfacing outliers, which had the most stable, and warmest, 
temperature regimes, were also the nearest to the main sett, at only $34 \mathrm{~m}$ and $65 \mathrm{~m}$ away, respectively, compared to 131, 189, and $402 \mathrm{~m}$ for the other three outliers (Table 2). Cubs born at these warmer and nearer outliers persisted in the population record at these outliers, while conspecifics born at southwest-facing outliers located at the edge of the territory, which had continuously cooler temperature profiles, disappeared from further trapping records and were assumed to have died [41]. Potentially, where outliers are nearby, cubs can be evacuated from the main sett more easily at times of threat at the main sett $[17,18,60]$. Indeed, another north-westfacing outlier was always warm, but perhaps due to its greater distance from the main sett $(402 \mathrm{~m})$ no cubs were recorded there.

This study also highlights that replacing a "natural" sett with an "artificial" sett to mitigate the loss of a sett to development may not effectively compensate the resident social group. That is, the thermal "qualities" within artificial setts, from the examples we investigated, were significantly inferior to natural setts. These data we present linking cub persistence to sett thermal characteristics suggest strongly that artificial setts may not provide such a suitable breeding environment as natural ones, though no records of the breeding success of these particular artificial setts were available.

In terms of sett quality, soil temperature varies predictably with depth in specified soil types [61]. In natural badger setts, a significant negative correlation has been noted between a vertical depth of sampling points below the soil surface from $22.5 \mathrm{~cm}$ to $144 \mathrm{~cm}$, but with no significant correlation from $2 \mathrm{~m}$ to $6 \mathrm{~m}$ [62]. However, Oliver et al. [61] report that sub-soil temperature also varies with groundcover, with grassland areas showing more variability than forested areas, in terms of heat flux. They also report marked diurnal variations in subsoil temperatures. Indeed, even the presence or absence of canopy leaves can influence soil temperatures [63], by affecting wind speed over the soil surface.

Another feature of sett thermal dynamics was the tendency for barriers to exist between the tunnel system and nest chambers. Tree roots and barricades of bedding often obstructed the passage of our probe. Plausibly our probe reached chambers only in the artificial sett, where the plastic pipe and concrete chambers, combined with simple architecture, led to lower thermal efficiency. Even here, however, bedding/plastic sheet materials blocked some chambers. We qualify the observations we make here with the caveat that, while the internal microclimatic benefits of larger, natural, setts are demonstrably clear, there may be further thermal advantages associated with nesting (and natal) chambers which we were unable to measure assuredly using this technique. Precise measures of nest chambers would thus require the development of new instrumentation in the future.

It thus appears extremely difficult to undertake construction of a badger sett from artificial materials, potentially at an inferior site to the original sett, which has sufficient tunnel depth, complexity, and insulating ground cover to compensate fully for natural sett sites. Never-the-less, we hope that the information provided here might be instructive to consultants and conservation agencies concerned with designing optimal artificial setts in which badgers might succeed and breed.

\section{Acknowledgments}

The authors are extremely grateful to Dr. P. Johnson for helping with the statistics and for his comments on the manuscript. Many thanks go to Dr. M. D. Morecroft, Dr. M. E. Taylor and Dr. H. R. Oliver at the NERC Institute of Ecology \& Hydrology, Oxford University Field Laboratory, Wytham. The authors would like to thank everyone who helped with the collection of the Wytham badger trapping and sett data: Dr. G. McLaren, Dr. H. Dagdale, Dr. I. Montes, A. Kiss, and A. Renwick, and they are grateful to volunteers from the Earthwatch Institute for assisting with sett monitoring. Thanks are expressed to Dr. K. Service for her assistance with the Gloucestershire badger sett survey. Much of this study is supported by Japan Highway Landscape Association and the Toyota Foundation. Work was carried out under English Nature Licences, currently 20001537, and Home Office License, PPL 30/1216.

\section{References}

[1] D. R. Norris, M. T. Theberge, and J. B. Theberge, "Forest composition around wolf (Canis lupus) dens in eastern Algonquin Provincial Park, Ontario," Canadian Journal of Zoology, vol. 80, no. 5, pp. 866-872, 2002.

[2] W. B. Ballard, L. A. Ayres, C. L. Gardner, and J. W. Foster, "Den site activity patterns of gray wolves, Canis lupus, in south central Alaska," Canadian Field Naturalist, vol. 105, pp. 497$504,1991$.

[3] S. M. Nielson, V. Pederson, and B. B. Klitgard, "Arctic fox (Alopex lagopus) dens in the Disko Bay area, west Greenland," Arctic, vol. 47, pp. 327-333, 1994.

[4] C. A. S. Smith, C. M. M. Smits, and B. G. Slough, "Landform selection and soil modifications associated with Arctic fox (Alopex lagopus) den sites in Yukon Territory, Canada," Arctic \& Alpine Research, vol. 24, no. 4, pp. 324-328, 1992.

[5] M. J. Chamberlain and B. D. Leopold, "Movements and space use of gray foxes (Urocyon cinereoargenteus) following mate loss," American Midland Naturalist, vol. 147, no. 2, pp. 409412, 2002.

[6] G. M. Durner, S. C. Amstrup, and K. J. Ambrosius, "Remote identification of polar bear maternal den habitat in northern Alaska," Arctic, vol. 54, no. 2, pp. 115-121, 2001.

[7] B. G. Slough, "Characteristics of Canada Lynx, Lynx canadensis, maternal dens and denning habitat," Canadian FieldNaturalist, vol. 113, no. 4, pp. 605-608, 1999.

[8] A. J. Magoun and J. P. Copeland, "Characteristics of wolverine reproductive den sites," Journal of Wildlife Management, vol. 62, no. 4, pp. 1313-1320, 1998.

[9] S. A. Johnson and K. A. Berkley, "Construction of a natal den by an introduced river otter, Lutra canadensis, in Indiana," Canadian Field-Naturalist, vol. 113, no. 2, pp. 301-304, 1999.

[10] K. R. Crooks, "Den-site selection in the island spotted skunk of Santa Cruz Island, California," Southwestern Naturalist, vol. 39, no. 4, pp. 354-357, 1994. 
[11] D. E. Wilson and D. M. Reeder, Eds., Mammal Species of the World. A Taxonomic and Geographic Reference, The Johns Hopkins University Press, London, UK, 3rd edition, 2005.

[12] H. Kruuk, "Spatial organization and territorial behaviour of the European badger Meles meles L.," Journal of Zoology, vol. 184, pp. 1-19, 1978.

[13] C. P. Doncaster and R. Woodroffe, "Den site can determine shape and size of badger territories: implications for groupliving," Oikos, vol. 66, no. 1, pp. 88-93, 1993.

[14] E. Neal and C. L. Cheeseman, Badgers, T. \& A. D. Poyser, London, UK, 1996.

[15] P. A. Fowler and P. A. Racey, "Overwintering strategies of the badger, Meles meles, at $57^{\circ} \mathrm{N}$," Journal of Zoology, vol. 214, pp. 635-651, 1988.

[16] D. D. P. Johnson, D. W. Macdonald, and A. J. Dickman, "An analysis and review of models of the sociobiology of the Mustelidae," Mammal Review, vol. 30, no. 3-4, pp. 171-196, 2000.

[17] H. Kruuk, The Social Badger: Ecology and Behaviour of a Group-Living Carnivore (Meles meles), Oxford University Press, Oxford, UK, 1989.

[18] R. Woodroffe and D. W. Macdonald, "Badger socialitymodels of spatial grouping," Symposium of the Zoological Society of London, vol. 65, pp. 145-169, 1993.

[19] S. Jenkinson and C. P. Wheater, "The influence of public access and sett visibility on badger (Meles meles) sett disturbance and persistence," Journal of Zoology, vol. 246, no. 4, pp. 478-482, 1998.

[20] E. Virgós and J. G. Casanovas, "Badger Meles meles sett site selection in low density Mediterranean areas of central Spain," Acta Theriologica, vol. 44, no. 2, pp. 173-182, 1999.

[21] R. Kowalczyk, A. N. Bunevich, and B. Jedrzejewska, "Badger density and distribution of setts in Bialowieza Primeval Forest (Poland and Belarus) compared to other Eurasian populations," Acta Theriologica, vol. 45, no. 3, pp. 395-408, 2000.

[22] A. Wright, A. H. Fielding, and C. P. Wheater, "Predicting the distribution of Eurasian badger (Meles meles) setts over an urbanized landscape: a GIS approach," Photogrammetric Engineering and Remote Sensing, vol. 66, no. 4, pp. 423-428, 2000.

[23] R. F. Hammond, G. McGrath, and S. W. Martin, "Irish soil and land-use classifications as predictors of numbers of badgers and badger setts," Preventive Veterinary Medicine, vol. 51, no. 3-4, pp. 137-148, 2001.

[24] E. Revilla, F. Palomares, and N. Fernández, "Characteristics, location and selection of diurnal resting dens by Eurasian badgers (Meles meles) in a low density area," Journal of Zoology, vol. 255, no. 3, pp. 291-299, 2001.

[25] T. C. Good, K. Hindenlang, S. Imfeld, and B. Nievergelt, "A habitat analysis of badger (Meles meles L.) setts in a seminatural forest," Mammalian Biology, vol. 66, no. 4, pp. 204214,2001

[26] D. W. Macdonald, C. Newman, J. Dean, C. D. Buesching, and P. J. Johnson, "The distribution of Eurasian badger, Meles meles, setts in a high-density area: field observations contradict the sett dispersion hypothesis," Oikos, vol. 106, no. 2, pp. 295307, 2004.

[27] P. S. Thornton, "Density and distribution of badgers in south west England-a predictive model," Mammal Review, vol. 18, pp. 11-23, 1988.
[28] D. W. Macdonald, P. D. Stewart, P. Stopka, and N. Yamaguchi, "Measuring the dynamics of mammalian societies: an ecologist's guide to ethological methods," in Research Techniques in Animal Ecology: Controversies and Consequences, L. Boitani and T. K. Fuller, Eds., pp. 332-388, Columbia University Press, New York, NY, USA, 2000.

[29] R. J. Fell, C. D. Buesching, and D. W. Macdonald, "The social integration of European badger (Meles meles) cubs into their natal group," Behaviour, vol. 143, no. 6, pp. 683-700, 2006.

[30] D. W. Macdonald, C. Newman, C. D. Buesching, and P. J. Johnson, "Male-biased movement in a high-density population of the Eurasian badger (Meles meles)," Journal of Mammalogy, vol. 89, no. 5, pp. 1077-1086, 2008.

[31] P. Reason, S. Harris, and P. Cresswell, "Estimating the impact of past persecution and habitat changes on the numbers of badgers Meles meles in Britain," Mammal Review, vol. 23, no. 1, pp. 1-15, 1993.

[32] P. Cresswell, W. J. Cresswell, and M. J. Woods, Bunkers and dream Homes for Badgers - the Country Life Guide to Artificial Badger Setts, The National Federation of Badger Groups / Badger Trust, London, UK, 1993.

[33] R. H. G. Jongman, "The context and concept of ecological networks," in Ecological Networks and Greenways. Concept, Design, Implementation, Jongman R. H. G. and G. Pungetti, Eds., pp. 7-33, Cambridge University Press, Cambridge, UK, 2004.

[34] B. Iuell, G. J. Bekker, R. Cuperus et al., Wildlife and Traffic: A European Handbook for Identifying Conflicts and Designing Solution, KNNV, Brussels, Belgium, 2003.

[35] C. Newman, D. W. Macdonald, and M. A. Anwar, "Coccidiosis in the European badger, Meles meles in Wytham Woods: infection and consequences for growth and survival," Parasitology, vol. 123, no. 2, pp. 133-142, 2001.

[36] D. W. Macdonald and C. Newman, "Population dynamics of badgers (Meles meles) in Oxfordshire, U.K.: numbers, density and cohort life histories, and a possible role of climate change in population growth," Journal of Zoology, vol. 256, no. 1, pp. 121-138, 2002.

[37] T. J. Roper, "Badger Meles meles setts-architecture, internal environment and function," Mammal Review, vol. 22, no. 1, pp. 43-53, 1992.

[38] T. J. Roper and I. Kemenes, "Effect of blocking of entrances on the internal environment of badger Meles meles setts," Journal of Applied Ecology, vol. 34, no. 5, pp. 1311-1319, 1997.

[39] K. Kilshaw, C. Newman, C.D. Buesching, J. Bunyan, and D. W. Macdonald, "Investigating coordinated latrine use by European badgers, Meles meles: potential consequences for territorial defence," Journal of Mammalogy, vol. 90, pp. 11881198, 2009.

[40] H. Kruuk, "Foraging and spatial organisation of the European badger, Meles meles L.," Behavioral Ecology and Sociobiology, vol. 4, no. 1, pp. 75-89, 1978.

[41] D. W. Macdonald, C. Newman, P. Nouvellet, and C.D. Buesching, "An analysis of Eurasian badger (Meles meles) population dynamics: implications for regulatory mechanisms," Journal of Mammalogy, vol. 90, pp. 1392-1403, 2009.

[42] C. L. Cheeseman and S. S. Harris, "Methods of marking badgers (Meles meles)," Journal of Zoology, vol. 197, pp. 289292, 1982.

[43] R. J. Delahay, J. A. Brown, P. J. Mallinson et al., "The use of marked bait in studies of the territorial organization of the European Badger (Meles meles)," Mammal Review, vol. 30, no. 2, pp. 73-87, 2000. 
[44] D. W. Macdonald, C. Newman, P. D. Stewart, X. DomingoRoura, and P. J. Johnson, "Density-dependent regulation of body mass and condition in badgers (Meles meles) from Wytham Woods, Oxfordshire," Ecology, vol. 83, no. 7, pp. 2056-2061, 2002.

[45] P. J. Jarman, "The social organization of antelope in relation to their ecology," Behaviour, vol. 48, pp. 215-266, 1977.

[46] L. M. Rogers, C. L. Cheeseman, P. J. Mallinson, and R. CliftonHadley, "The demography of a high-density badger (Meles meles) population in the west of England," Journal of Zoology, vol. 242, no. 4, pp. 705-728, 1997.

[47] M. Efford, "Comment-revised estimates of the bias in minimum number alive estimator," Canadian Journal of Zoology, vol. 70, pp. 628-631, 1992.

[48] M. A. Pryde, C. F. J. O’Donnell, and R. J. Barker, "Factors influencing survival and long-term population viability of New Zealand long-tailed bats (Chalinolobus tuberculatus): implications for conservation," Biological Conservation, vol. 126, no. 2, pp. 175-185, 2005.

[49] H. L. Dugdale, D. W. Macdonald, L. C. Pope, and T. Burke, "Polygynandry, extra-group paternity and multiple-paternity litters in European badger (Meles meles) social groups," Molecular Ecology, vol. 16, no. 24, pp. 5294-5306, 2007.

[50] H. L. Dugdale, D. W. Macdonald, L. C. Pope, P. J. Johnson, and T. Burke, "Reproductive skew and relatedness in social groups of European badgers, Meles meles," Molecular Ecology, vol. 17, no. 7, pp. 1815-1827, 2008.

[51] D. R. Webb and J. R. King, "Effects of wetting of insulation of bird and mammal coats," Journal of Thermal Biology, vol. 9, no. 3, pp. 189-191, 1984.

[52] T. R. Oke, Boundary Layer Climates, Methuen, London, UK, 1978.

[53] D. R. Webb, W. P. Porter, and P. A. McClure, "Development of insulation in juvenile rodents: functional compromise in insulation," Functional Ecology, vol. 4, no. 2, pp. 251-256, 1990.

[54] R. Hewson, "Distribution and density of fox breeding dens and the effects of management," Journal of Applied Ecology, vol. 23, no. 2, pp. 531-538, 1986.

[55] P. Ciucci and L. D. Mech, "Selection of wolf dens in relation to winter territories in northeastern Minnesota," Journal of Mammalogy, vol. 73, no. 4, pp. 899-905, 1992.

[56] N. Fernández and F. Palomares, "The selection of breeding dens by the endangered Iberian lynx (Lynx pardinus): implications for its conservation," Biological Conservation, vol. 94, no. 1, pp. 51-61, 2000.

[57] P. D. Stewart, L. Bonesi, and D. W. Macdonald, "Individual differences in den maintenance effort in a communally dwelling mammal: the Eurasian badger," Animal Behaviour, vol. 57, no. 1, pp. 153-161, 1999.

[58] R. F. Ewer, The Carnivores, Cornell University Press, Ithaca, NY, USA, 1973.

[59] R. M. Anderson and W. Trewhella, "Population dynamics of the badger (Meles meles) and the epidemiology of bovine tuberculosis (Mycobacterium bovis)," Philosophical transactions of the Royal Society of London. Series B, vol. 310, no. 1145, pp. 327-381, 1985.

[60] W. J. Cresswell, S. Harris, C. L. Cheeseman, and P. J. Mallinson, "To breed or not to breed: an analysis of the social and densitydependent constraints on the fecundity of female badgers (Meles meles)," Philosophical transactions of the Royal Society of London. Series B, vol. 338, no. 1286, pp. 393-407, 1992.
[61] S. A. Oliver, H. R. Oliver, J. S. Wallace, and A. M. Roberts, "Soil heat flux and temperature variation with vegetation, soil type and climate," Agricultural and Forest Meteorology, vol. 39, no. 2-3, pp. 257-269, 1987.

[62] J. A. H. Moore and T. J. Roper, "Temperature and humidity in badger Meles meles setts," Mammal Review, vol. 33, no. 3-4, pp. 308-313, 2003.

[63] M. D. Morecroft, M. E. Taylor, and H. R. Oliver, "Air and soil microclimates of deciduous woodland compared to an open site," Agricultural and Forest Meteorology, vol. 90, no. 1-2, pp. 141-156, 1998. 

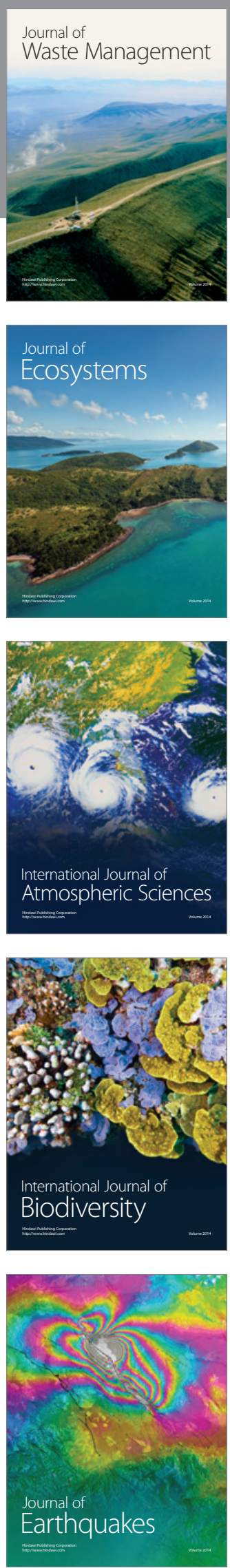
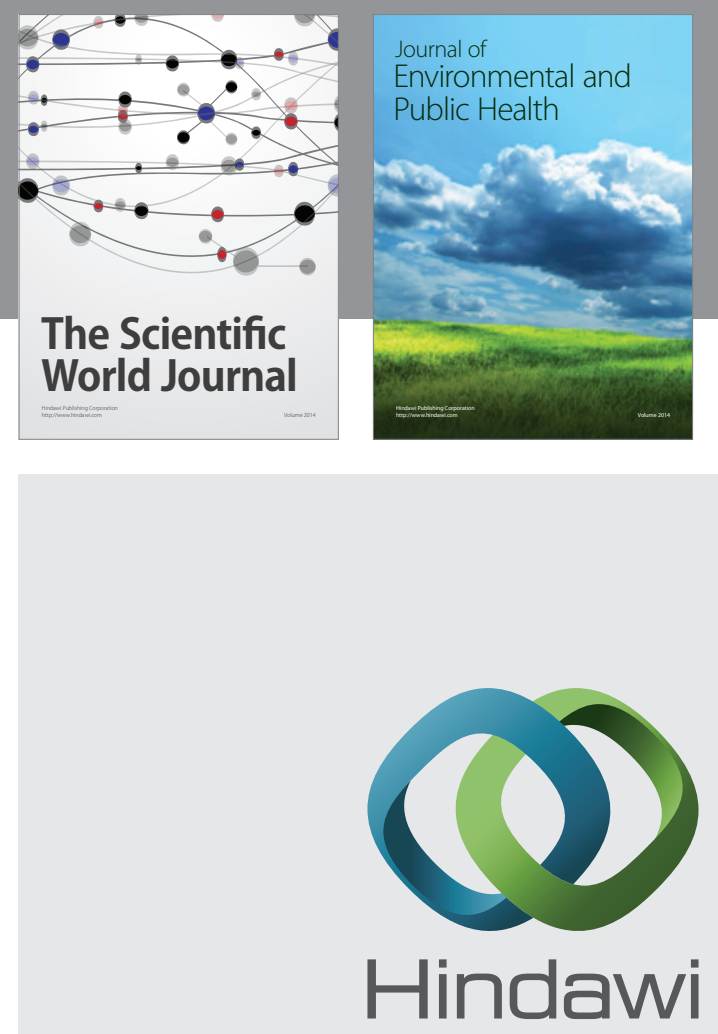

Submit your manuscripts at

http://www.hindawi.com
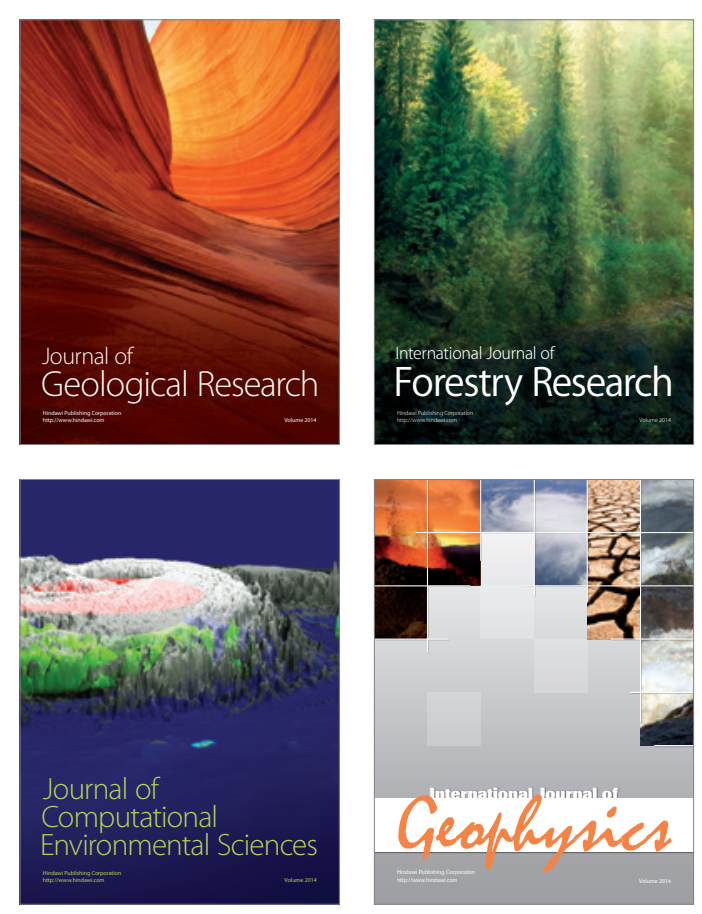
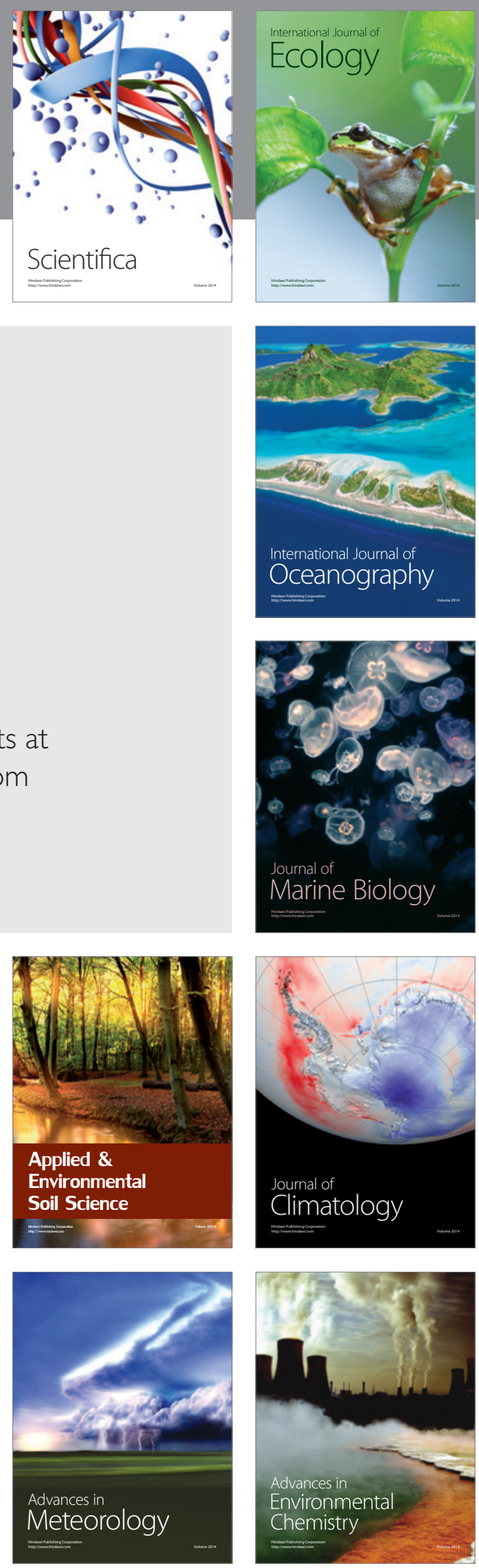